\title{
THE RELATION BETWEEN SPEED-LANE CHOICE AND ROAD ACCIDENTS IN JORDAN
}

\author{
Lina Shbeeb, Wa'el Awad, Mohd R. Suliman \\ Civil Engineering Department, Faculty of Engineering Technology \\ Al Balqa' Applied University \\ Amman, Jordan \\ E-mail: $\underline{\text { linash@,nets.com.jo }}$ \\ Jamil Mujahed \\ Jordan Traffic Institute \\ Amman, Jordan
}

\begin{abstract}
Summary: More than $96 \%$ of traffic casualties in Jordan take place on nonintersection roadway segments. Speed variation and improper lane change are considered to be some of the main factors contributing to these casualties. This research paper describes an attempt made to study speed-lane choice behavior in Jordan. Drivers' behaviors with regard to their choice of speed and/or traveled lane are assessed. One-fifth of the observed drivers are speeding and one-forth of them changes lanes along the tested segment. Two models are developed and investigated to describe the relationships between speed and lane choice using binary and linear regression models. Results indicate that driving behavior varies with respect to roadway geometry and lane. Speed influences the driver choice of lane changing and his/her decision about changing lanes influences his/her speed choice.
\end{abstract}

\section{INTRODUCTION}

Driving above speed limit and improper lane changing are among the most frequent types of traffic violations found to contribute to road traffic accidents in Jordan. There are 97 and 28 reported fatalities attributed to improper lane changing and speeding (JTI, 2004). The total number of road traffic fatalities reported in Jordan was 832 , which means that $15 \%$ of road fatalities are related to these types of violations.

Little research has focused on the factors affecting speed and lane choice and their relation to traffic accidents in Jordan. Many similar attempts have been made in the USA and Europe to investigate speeding and lane choice and their relation to accident expectations (Berge and Vaa, 2003; Botma, 1999; Corbett, 2001; Haglund and Aberg, 2000; 2002; Hauer and Ahlin, 1982; Papp et al., 1996; Shinar, 2001; Wei, et al., 2000).

\section{OBJECTIVES}

The main objective of this research paper is to investigate the factors affecting driver speed and/or lane change choice. Tested variables include number of lanes, headways, average speed, acceleration, deceleration, traffic volumes and composition. In addition, driver behavior related to choice of speed and traveled lane is examined. Accident records related to speeding and/or wrong lane choice and fatal accident are briefly discussed. 


\section{SCOPE AND METHODOLOGY}

\section{Site Selection}

Five segments are identified for data collection on two major highways connecting the Capital Amman and Al-Zarka City. Four of the segments are chosen outside the Capital, while the fifth is selected within the city. Each segment is located on a multilane divided highway near a pedestrian overpass. The selected segments are straight with adequate sight distance and proper marking. The lengths of segments ranged from 100 to 300 meters.

The first location at the Amman-Al Zarka highway near the Faculty of Engineering Technology campus is a six-lane divided highway with $80 \mathrm{~km} / \mathrm{h}$ speed limit. The second location is located at the Ring road surrounding Amman near Marka. The Ring road consists of a four-lane divided highway with an $80 \mathrm{~km} / \mathrm{h}$ speed limit. The third location is selected at the beginning of AmmanAl Zarka Highway near Sport City. This segment is a four-lane divided highway with a $70 \mathrm{~km} / \mathrm{h}$ speed limit.

\section{Data Collection}

Data was collected for three hours (daytime) at each segment during working days in February, 2005. Sunny weather and dry pavement conditions were prevailing. The data collection process was carefully prepared to simultaneously execute and verify the different tasks involved. The collection of data was accomplished during off-peak to allow the gathering of data related to lane change possibility and speeding. Observations were made for one lane at a time at interval periods of 5-10 minutes. In addition, a video camera was used to capture the lane change activity and speeding by subject drivers.

Five groups of observers were asked to collect data related to the task they were assigned to fulfill. Task group I was responsible for recording arrival time of each vehicle entering the test segment. Observers recorded if a lane change took place, use of mobile phone and seat-belt, the presence of pedestrian in the vicinity. Task group II was asked to collect data on speed of the vehicle entering the segment using radar guns, the availability of suitable gap to perform lane changing, the actual conducting of lane-changing. The same task group was asked at a different time to record the speed of vehicles changing their lane, the speed of leading vehicle, speed of adjacent vehicle. Task group III observed all lane-change maneuvers and reported whether the driver was signaling, deceleration, acceleration and the success of his/her maneuver. Task group IV accompanied with a police patrol was asked to interview a random sample of subject drivers. The interview included the purpose of their trip and whether they were speeding and/or changing their lane in their last kilometer. If driver admitted to speeding and/or changing lanes, he/she was asked to explain why. Information on driver gender, age, was also reported. Vehicle and license plate types were recorded for all observations.

Task group V conducted manual traffic counting classified into three classes of vehicles (passenger car, bus and truck). The classified counting was based on short-period counts of five minutes, which was verified against data collected by installing traffic counting devices on the tested segments. 


\section{Data Description}

The collected field observations include 3,048 headways, 1,700 speed readings, 1,152 lane change maneuvers observation, 331 personal interviews, and 127 five-minute traffic counts.

The data was stratified into two main categories based on geometric class. Class I includes all segments with three lanes per direction. Class II includes segments with two lanes per direction. Furthermore, the data were coded based on driver action in terms of lane change and speeding (driving above speed limit or not).

Speed Data. The collected data indicated that $20 \%$ of the drivers were speeding. Regardless of lane position, the average speed was below the posted speed limit for both classes of roadway (Table 1). The $85^{\text {th }}$ percentile speed was higher than the posted speed limit for the left lane at both Class I and Class II segments and for the middle lane in Class I, while it was below the posted speed for the right lane. Speed variation was found to be statistically significant by lane for Class II segments $\left(\mathrm{F}_{1,16}=32.4, \mathrm{p}=0.00\right)$. On the other hand, the variation was not statistically significant for Class I segments $\left(\mathrm{F}_{2,12}=1.95, \mathrm{p}=0.019\right)$.

Table 1. Speed variation by geometric class and lane

\begin{tabular}{|l|l|c|c|c|c|c|c|c|}
\hline $\begin{array}{l}\text { Geometric } \\
\text { class }\end{array}$ & Lane & $\begin{array}{c}\text { Number of } \\
\text { observations }\end{array}$ & $\begin{array}{c}\text { Average } \\
\text { Mean } \\
(\mathrm{km} / \mathrm{h})\end{array}$ & $\begin{array}{c}85^{\text {th }} \\
\text { percentile } \\
\text { speed }(\mathrm{km} / \mathrm{h})\end{array}$ & $\begin{array}{c}\text { Posted speed } \\
\text { limit }(\mathrm{km} / \mathrm{h})\end{array}$ & $\begin{array}{c}\text { Minimum } \\
(\mathrm{km} / \mathrm{h})\end{array}$ & $\begin{array}{c}\text { Maximum } \\
(\mathrm{km} / \mathrm{h})\end{array}$ & $\begin{array}{c}\text { Standard } \\
\text { Deviation } \\
(\mathrm{km} / \mathrm{h})\end{array}$ \\
\hline \multirow{4}{*}{ Class I } & Left & 183 & 73.5 & 89 & 80 & 36 & 128 & 15.6 \\
\cline { 2 - 9 } & Middle & 182 & 66.9 & 84 & 80 & 25 & 111 & 15.2 \\
\cline { 2 - 9 } & Right & 155 & 59.9 & 73 & 80 & 20 & 94 & 12.9 \\
\cline { 2 - 9 } & Total & 520 & 67.1 & 84 & 80 & 20 & 128 & 15.6 \\
\hline \multirow{3}{*}{ Class II } & Left & 565 & 71.9 & 86 & $70-80^{*}$ & 17 & 118 & 14.0 \\
\cline { 2 - 9 } & Right & 615 & 56.3 & 68 & $70-80$ & 16 & 113 & 12.0 \\
\cline { 2 - 9 } & Total & 1180 & 63.7 & 80 & $70-80$ & 16 & 118 & 15.1 \\
\hline
\end{tabular}

* 2 segments have a posted speed of $80 \mathrm{~km} / \mathrm{h}$ and one segment has $70 \mathrm{~km} / \mathrm{h}$

The highest proportion of drivers doing a speed above the posted speed is reported on the left lane, with 34\% and 36\% for Class I and Class II respectively (Table 2). Fewer cases are reported on the right lane. Chi-Square tests showed that there is a significant difference between driver speed-choice that can be attributed to the lane position $\left(\chi^{2}=48.3, \mathrm{p}=0.00\right.$ for Class I and $\chi^{2}=181, \mathrm{p}=0.00$ for Class II).

The data indicated that the average speed difference between the leading vehicle and the vehicle that changes its lane is $10 \mathrm{~km} / \mathrm{h}$, and most likely the driver decided to change his/her lane if the speed of the vehicle on the adjacent lane was slow. On average, the speed of vehicles that changed lanes was higher than the speed of the adjacent vehicle by $14 \mathrm{~km} / \mathrm{h}$.

Lane-Changing data. Lane changes are more frequent on Class I roadways than on Class II. On average, Class I experienced 3 lane-change maneuvers per minute compared to 2 lane-change maneuvers per minute for Class II. Collected data showed that the total number of lane changing maneuvers performed during the observation period is equally distributed between lanes for 
Class I but not Class II, where $63 \%$ of the lane changes are reported in the right lane (Table 3 ). Interestingly, $19 \%$ of observed lane changes in the left lane of Class I ended on the right lane, which implies that they cross more than one lane. A higher proportion of drivers in the middle lane changed their lane to the left lane to accelerate, and $20 \%$ of them used the right lane also for acceleration. High proportion of drivers used the shoulder for lane changing and mainly for deceleration. Still, $20 \%$ of drivers in the right lane of Class II used the shoulder for acceleration.

Table 2. Vehicle speeding by geometric class and lane

\begin{tabular}{|c|c|c|c|c|}
\hline Class & Lane & No Speeding & Speeding & Total \\
\hline \multirow{3}{*}{ Class I } & Left & $120(66 \%)$ & $63(34 \%)$ & 183 \\
\hline & Middle & $145(80 \%)$ & $37(20 \%)$ & 182 \\
\hline & Right & $149(96 \%)$ & $6(4 \%)$ & 155 \\
\hline \multicolumn{2}{|c|}{ Total number in class I } & $414(80 \%)$ & $106(20 \%)$ & 520 \\
\hline \multirow{2}{*}{ Class II } & Left & $364(64 \%)$ & $201(36 \%)$ & 565 \\
\hline & Right & $587(95 \%)$ & $28(5 \%)$ & 615 \\
\hline \multicolumn{2}{|c|}{ Total number in class II } & $951(81 \%)$ & $229(19 \%)$ & 1180 \\
\hline \multicolumn{2}{|l|}{ Total number } & $1365(80 \%)$ & $335(20 \%)$ & 1700 \\
\hline
\end{tabular}

Table 3. Lane-changing by geometric class, observed lane and by destination-lane

\begin{tabular}{|l|l|c|c|c|c|}
\hline Class & Lane & Left & Middle & Right & Grand Total \\
\hline \multirow{3}{*}{ Class I } & Left & $4(2 \%)$ & $149(78 \%)$ & $37(19 \%)$ & 190 \\
\cline { 2 - 6 } & Middle & $107(56 \%)$ & & $85(44 \%)$ & 192 \\
\cline { 2 - 6 } & Right & $11(6 \%)$ & $80(41 \%)$ & $105(54 \%)$ & 196 \\
\hline Total number in class I & $122(21 \%)$ & $229(40 \%)$ & $227(39 \%)$ & 578 \\
\hline \multirow{2}{*}{ Class II } & Left & $8(4 \%)$ & & $202(96 \%)$ & 210 \\
\cline { 2 - 7 } & Right & $186(51 \%)$ & & $178(49 \%)$ & 364 \\
\hline Total number in class II & $194(34 \%)$ & & $380(66 \%)$ & 574 \\
\hline Total number & $316(27 \%)$ & $229(20 \%)$ & $607(53 \%)$ & 1152 \\
\hline
\end{tabular}

Chi-Square tests showed a significant difference between lane-changing maneuvers attributed to lane position $\left(\chi^{2}=23.5, \mathrm{p}=0.00\right.$ for Class I and $\chi^{2}=23.6, \mathrm{p}=0.00$ for Class II).

Traffic Volume data. Traffic counts and composition are collected for each lane by geometric class (Table 4). Traffic composition showed that trucks are not as frequent in the left lane as they are in the right lane. Although buses are expected to stop more frequently, still a considerable proportion of them are using left lane. Around 9\% of traffic in left lane of Class I is buses while the corresponding ratio for Class II is only $2 \%$.

Table 4. 15-minutes volume statistics by geometric class and lane

\begin{tabular}{|l|l|c|c|c|c|}
\hline $\begin{array}{l}\text { Geometric } \\
\text { class }\end{array}$ & Lane & Mean (veh) & Standard Deviation & Bus percentage & Truck percentage \\
\hline \multirow{3}{*}{ Class I } & Left & 475.0 & 22.9 & 8.8 & 5.5 \\
\cline { 2 - 6 } & Middle & 513.7 & 50.3 & 12.4 & 20.1 \\
\cline { 2 - 6 } & Right & 552.6 & 69.7 & 14.6 & 25.3 \\
\hline \multirow{2}{*}{ Class II } & Left & 415.1 & 175.5 & 2.0 & 18.3 \\
\cline { 2 - 6 } & Right & 406.2 & 153.0 & 3.8 & 34.9 \\
\hline
\end{tabular}


Table 4 suggests that traffic volume In the left lane of Class I is lower than the other lanes. The difference between left lane and right lane for Class I is marginal. The difference in volumes among lanes is not statistically significant for either of the two classes. The hourly traffic volume on the selected segments ranges from $144 \mathrm{vphpl}$ to $1572 \mathrm{vphpl}$.

\section{FINDINGS}

The models developed consider modeling individual behavior and modeling data at a more general level by aggregating the collected data for each observation period. Correlation and regression analyses were conducted. Correlation analysis is based only on aggregate data while regression analysis considers both databases.

\section{Correlation Analysis}

Speed Choice. Testing the correlation of speed choice (speeding or not) with other variables showed different results according to geometric class. Speed choice, however, is found to be significantly correlated with number of vehicles that are not making lane changes $(\mathrm{r}=0.63)$, average speed $(\mathrm{r}=0.66)$, lane change possibility $(\mathrm{r}=0.58)$, and number of accelerating actions $(\mathrm{r}=0.84)$ for Class I, while the average speed is the only significant variable for Class II $(\mathrm{r}=0.73)$.

Lane Choice. Significant correlations are only reported between the variable that describes the no-lane change (lane-keeping) as an indicator of lane-choice and other variables. Testing the correlation of no lane change with other variables showed different results based on geometric class. For Class I, a significant relationship was found with volume $(\mathrm{r}=-0.81)$, number of notspeeding vehicles $(\mathrm{r}=0.78)$, number of speeding vehicles $(\mathrm{r}=0.63)$, and number of accelerating vehicles $(\mathrm{r}=0.58)$. For Cass II, headway $(\mathrm{r}=-0.59)$, lane change possibility $(\mathrm{r}=0.9)$, and number of speeding vehicles $(r=0.90)$ showed a significant relationship at a 95\% level of confidence.

\section{Regression Analysis}

Linear and binary logistic regressions were used in data analysis to develop mathematical models that explain the speed/lane choice behavior of drivers. Logistic binary regression is used to explore individual driver behavior related to speed/lane choice. On the other hand, linear regression is used to investigate overall relation between the different variables. Both types of regressions are briefly discussed in the following sub-sections.

\section{Linear Regression Analysis}

Two groups of linear regression models were developed, the first was by geometric class and the second by lane. Tables 5 and 6 show regression analysis completed by considering the number of speeding vehicles as a dependent variable. Tables 7 and 8 show the results of regression analysis related to lane changing by considering the number of vehicles not changing their lanes as a dependent variable.

Speed Choice. Speed and lane-change possibility are the independent variables that showed significant relationship for both geometric classes (Table 5). No statistically significant relationship is found to predict the number of speeding vehicles in the right lane, while in the 
case of the middle and left lane, the number of speeding vehicles were statistically significant with the volume on the adjacent lane (Table 6).

Table 5. Linear models by geometric class for speeding as dependent variable

\begin{tabular}{|l|l|c|c|c|}
\hline Geometric class & Model & Coefficient & T-calculated & P-value \\
\hline Class I & Constant & -45.30 & -4.61 & 0.001 \\
& Average speed & 0.66 & 4.75 & 0.001 \\
& Lane change possibility & 0.96 & 4.18 & 0.002 \\
\hline \multirow{2}{*}{ Class II } & Constant & -94.40 & -10.48 & 0.000 \\
& Average speed & 1.38 & 11.89 & 0.000 \\
& Lane change possibility & 0.68 & 8.03 & 0.000 \\
\hline
\end{tabular}

Table 6. Linear models by lane for speeding as dependent variable

\begin{tabular}{|l|l|c|c|c|}
\hline Lane & Model & Coefficient & T-calculated & P-value \\
\hline Left & Constant & 173.82 & 16.7 & 0.038 \\
& Volume on middle lane & -0.85 & -14.8 & 0.043 \\
\hline \multirow{2}{*}{ Middle } & Constant & 93.46 & 210 & 0.003 \\
& Volume on left lane & -0.42 & -192 & 0.003 \\
\hline Right & Constant & 6.09 & 2.59 & 0.041 \\
& Headway & -0.29 & -1.09 & 0.317 \\
\hline
\end{tabular}

Lane-Choice. Number of speeding vehicles and headway are the independent variables that showed significant relationships for geometric Classes I \& I I, respectively (Table 7). On the other hand, models by lane are different due to their position on the carriageway. The number of speeding vehicles is statistically significant for the left lane, while the number of not-speeding vehicles is statistically significant for the middle lane. Lane-change possibility is the independent variable that is significant for the right lane (Table 8).

Table 7. Linear models by geometric class for no lane change as dependent variable

\begin{tabular}{|l|l|c|c|c|}
\hline Geometric class & Model & Coefficient & T-calculated & P-value \\
\hline Class I & Constant & 12.80 & 2.41 & 0.033 \\
& Speeding & 1.20 & 2.81 & 0.016 \\
\hline \multirow{2}{*}{ Class II } & Constant & 81.80 & 7.88 & 0.000 \\
& Headway & -4.32 & -2.93 & 0.010 \\
\hline
\end{tabular}

Table 8. Linear models by lane for no lane change as dependent variable

\begin{tabular}{|l|l|c|c|c|}
\hline Lane & Model & Coefficient & T-calculated & P-value \\
\hline Left & Constant & 24.64 & 2.98 & 0.011 \\
& Speeding & 1.04 & 2.88 & 0.014 \\
\hline \multirow{2}{*}{ Middle } & Constant & 2.07 & 0.26 & 0.811 \\
& No speeding & 0.76 & 3.43 & 0.042 \\
\hline \multirow{2}{*}{ Right } & Constant & 12.75 & 3.09 & 0.009 \\
& Lane change possibility & 1.42 & 7.59 & 0.000 \\
\hline
\end{tabular}




\section{Binary Logistic Regression Analysis}

Logistic regression analysis is applied to investigate speed choice and lane choice at the individual level. The dependent variable in the speed choice model is a binary variable with a value of 1 if the driver exceeds the posted speed limit and 0 otherwise. The dependent variable in lane choice model is also a binary variable of a value 1 if the driver changes his/her lane and 0 otherwise. A number of variables are considered while developing these models at either geometry class level of the tested segments or for various traffic lanes on each segment. Independent variables that are significantly related to the dependent variables are discussed below.

Speed Choice. Models developed for each geometry class indicated that the speed of the leading vehicle is statistically significantly related to the driver decision to drive above the speed limit. This is applicable for models developed for both classes. Lane-change possibility is found to be significantly related to driver decision to speed on Class II, but not on Class I (Table 9).

Table 9. Binary logistic models by geometry class for speeding as dependent variable

\begin{tabular}{|c|c|c|c|c|c|c|c|c|}
\hline $\begin{array}{c}\text { Geometry } \\
\text { class }\end{array}$ & Model & Parameter & $\begin{array}{c}\text { Coefficient } \\
\beta \\
\end{array}$ & $\begin{array}{c}\text { Standard } \\
\text { error }\end{array}$ & Wald & $\mathrm{df}$ & $\begin{array}{c}\mathrm{p}- \\
\text { value }\end{array}$ & $\operatorname{Exp}(\beta)$ \\
\hline \multirow{4}{*}{ Class I } & \multirow{2}{*}{1} & Speed of leading vehicle & 0.09 & 0.01 & 74.43 & 1 & 0 & 1.09 \\
\hline & & Constant & -7.54 & 0.76 & 98.26 & 1 & 0 & 0.001 \\
\hline & \multirow{2}{*}{2} & Lane-change possibility & 0.31 & 0.28 & 1.26 & 1 & 0.262 & 1.37 \\
\hline & & Constant & -1.61 & 0.25 & 41.01 & 1 & 0 & 0.2 \\
\hline \multirow{4}{*}{ Class II } & \multirow{2}{*}{1} & Speed of leading vehicle & 0.07 & 0.01 & 135.70 & 1 & 0 & 1.07 \\
\hline & & Constant & -6.108 & 0.43 & 203.11 & 1 & 0 & 0.002 \\
\hline & \multirow{2}{*}{2} & Lane-change possibility & 0.46 & 0.16 & 8.25 & 1 & 0.004 & 1.58 \\
\hline & & Constant & -1.72 & 0.13 & 168.58 & 1 & 0 & 0.18 \\
\hline
\end{tabular}

Models developed for each lane show that the action of lane-changing is related to the choice to speed on the right lane but not on other lanes. Lane-change possibility is found to be statistically significantly related with respect to driving above the speed limit regarding observations made on left lane.

Lane-Choice. Lane change possibility is statistically significantly related to the driver decision to change his/her lane. This is true for Class I and Class II. Driver speed seems to be related to the driver decision to change his/her lane for Class I segments. However, the statistical test failed to significantly prove that (Table 10).

Models developed for each lane show that the driver speed on the right lane influences his/her decision to change his/her lane. Possibility of lane-change available for drivers on the left lane is related to the actual performing of lane changing. 
Table 10. Binary logistic models by geometry class for lane-changing as dependent variable

\begin{tabular}{|c|c|c|c|c|c|c|c|c|}
\hline $\begin{array}{c}\text { Geometry } \\
\text { class }\end{array}$ & Model & Parameter & $\begin{array}{c}\text { Coefficient } \\
\beta\end{array}$ & $\begin{array}{l}\text { Standard } \\
\text { error }\end{array}$ & Wald & df & $\begin{array}{c}\mathrm{p}- \\
\text { value }\end{array}$ & $\operatorname{Exp}(\beta)$ \\
\hline \multirow{4}{*}{ Class I } & \multirow{2}{*}{1} & Lane-change possibility & 0.97 & 0.26 & 14.65 & 1 & 0 & 2.65 \\
\hline & & Constant & -1.38 & 0.23 & 34.73 & 1 & 0 & 0.25 \\
\hline & \multirow{2}{*}{2} & Speed & -0.01 & 0.006 & 3.39 & 1 & 0.066 & 0.99 \\
\hline & & Constant & 0.14 & 0.40 & 0.12 & 1 & 0.728 & 1.15 \\
\hline \multirow{4}{*}{ Class II } & \multirow{2}{*}{1} & Lane-change possibility & 1.16 & 0.18 & 42.33 & 1 & 0 & 3.19 \\
\hline & & Constant & -2.18 & 0.16 & 191.61 & 1 & 0 & 0.11 \\
\hline & \multirow{2}{*}{2} & Speed & 0.001 & 0.005 & 0.01 & 1 & 0.908 & 1.00 \\
\hline & & Constant & -1.39 & 0.31 & 19.83 & 1 & 0 & 0.25 \\
\hline
\end{tabular}

\section{Drivers' Interviews}

Speed Choice. Out of 331 interviewed drivers, 51 cases of speeding were reported. When asked about reasons for speeding, twenty two admitted that the reason is the lack of enforcement (no police is on-site). Twenty drivers, however, said the empty road is tempting to speed. Twelve drivers suggested that the posted speed is too low. Some confessed that speeding is their hobby (Figure 1).

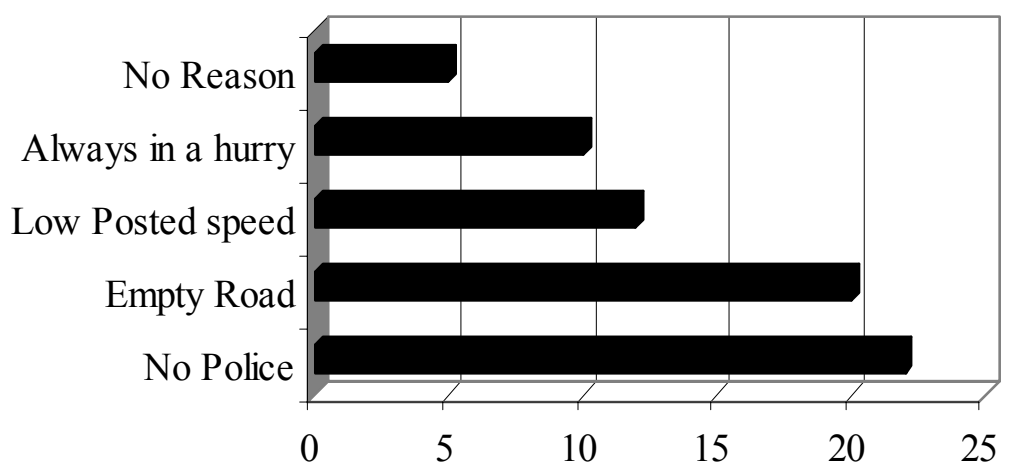

Figure 1. Drivers' answers for reasons behind their speeding

Lane choice. Thirty percent of the interviewed drivers admitted that they had changed lanes in the last kilometer before stopping prior to the interview. The reasons reported ranged from slow moving vehicle ahead to no police on-site. Many interviewed drivers admitted that they can carry on a lane-changing maneuver as long as it is allowed without any reason. Heavy or slow vehicles are the reason behind many lane-changes according to some interviewed drivers. Drivers believe that they can change lanes on high-speed open roads. Being in a hurry is frequent answer. Few drivers admit that lane-change is attributed to pollutants emitted by the leading vehicles.

\section{DISCUSSION OF FINDINGS}

At the national level, accident records showed that $20 \%$ of total fatalities attributed to speeding and lane changing occurred on straight roadway segments (similar to the studied locations) with $80 \mathrm{~km} / \mathrm{h}$ speed limits. Furthermore, $40 \%$ of road fatalities related to speeding and improper lanechange reported on through roads occurred on straight segments with $80 \mathrm{~km} / \mathrm{h}$ under prevailing 
conditions similar to those at studied locations. This suggests that speeding and lane-changing are contributing factors to fatal accidents for these types of roads.

This study indicated that $20 \%$ of observed drivers are speeding and $25 \%$ are changing lanes. Most of the speeding took place in the left and middle lanes for roadways with three-lanes in each direction. Speeding is not reported in right lane. Still, this lane is used for acceleration by traffic in the middle lane. Only $16 \%$ of all interviewed drivers admitted speeding. One third of them have driving experience ranging from 7 to 10 years. The proportion of those admitting speeding decrease as their experience increased. Similar explanations are given for speeding regardless of the age or driving experience, however.

The proportion of drivers who admitted lane-changing is $30 \%$, which is not far from the observed proportion. One-forth of the observed vehicles changed lanes while passing the tested segment.

The common explanation given for speeding and lane changing is the lack of police patrol on site, which clearly shows a potential violation of traffic rules in the absence of speed enforcement.

Geometric class influences the level of association between the tested variables. This is clearly indicated in the results. Analysis indicates that the possibility to maneuver is higher for Class I compared to Class II. This may be attributed to the variation in speed among lanes and volume distribution between adjacent lanes. Traffic characteristics are described by relatively low traffic volume and high speed. The opposite is true for the right lane. The traffic on Class II segments is nearly equally distributed between both lanes and therefore limits the possibility of lane changing. On the other hand, traffic volumes are not equally distributed between the different lanes on Class I segments, which increases the lane-changing possibilities.

Regression analysis showed that speeding is a statistically significant variable for speed/lane choice models. This is indicated in binary and linear regression models. Speeding of the leading vehicle is particularly significant when considering speed choice at the individual level. The developed models show that speed influences the decision to change lanes and vice versa.

\section{REFERENCES}

Berge, G., Vaa. (2003). Feeling of speed: a qualitative study reasons for speed choices. Report No: TOI-660/2003. Norwegian Institute of Transport Economics.

Botma, H. (1999). The free speed distribution of driver: Estimation approach. Proceedings of the 5th TRAIL Annual Congress 1999, Five Years Crossroads of Theory and Practice. Netherlands.

Corbett, C. (2001). Explanation for "understating" in self-reported speeding behaviour. Transportation Research. Part F: Traffic Psych \& Behaviour, 4(2): 133-150.

Haglund, M., Aberg, L. (2002). Stability in Drivers' speed choice. Journal: Transportation Research. Part F: Traffic Psych \& Behaviour, 5(3): 177-188.

Haglund, M., Aberg, L. (2000). Speed choice in relation to speed limit and influences from other drivers. Transportation Research. Part F: Traffic Psych \& Behaviour, 3(1): pp 39-51. 
Hauer, E., Ahlin, F.J. (1982). Speed Enforcement and speed choice. Accident analysis and prevention, 14(4): 267-278.

Jordan Traffic Institute “JTI.” (2004). Traffic Accident in Jordan 2004.

Papp, I., Siska, T., Hollo, P. (1996). Factors influencing the speed choice of drivers in Town. Proceedings of the Conference: Road Safety in Europe and Strategic Highway Research Program (SHRP). Report No: No. 4A, Part 2. Sweden: VTI publication.

Shinar, D. (2001). Driving speed relative to the speed limit and the relative to the perception of safe, enjoyable, and economical speed. Proceedings of International Conference: Traffic Safety on Three Continents. Moscow, Russia.

Wei, H., Lee, J., Li, Q., Li, C.J. (2000). Observation-based Lane-vehicle assignment hierarchy: microscopic simulation on urban street network. Transportation Research Record 1710: 96103. 